\title{
VALVE DYNAMICS IN RECIPROCATING COMPRESSORS FOR MOTOR VEHICLES
}

\author{
Dragan Taranović, Dobrivoje Ninković, Aleksandar Davinić, Radivoje Pešić, Jasna Glišović, Saša Milojević
}

Original scientific paper

Reliability and thermodynamic properties of reciprocating compressors are largely dependent on the valve. Since the valves open and close automatically, there is an intensive impact of the valve and the sealing element dynamics to the gas flow through the valve. Poor valve characteristics inevitably lead to degradation of compressor performance and/or short lifetime of the valve. A short lifetime of the valve is the result of excessive impact forces between the sealing element and other parts of the valve assembly. Matching the valves to the specific reciprocating compressor is a complex task that requires the use of appropriate mathematical models before the realization of the valve. The mathematical model for the prediction of the valve dynamics is presented within this paper. The mathematical model is verified by measurements of thermodynamic characteristics of the specific reciprocating compressor used in motor vehicles. It is concluded that the mathematical model agrees well with the results of laboratory tests.

Keywords: reciprocating compressor; valve dynamics; valve flow

Dinamika ventila stapnih kompresora za motorna vozila

Izvorni znanstveni članak

Pouzdanost i termodinamička svojstva stapnih kompresora uvelike ovise o ventilu. Budući da se ventili otvaraju i zatvaraju automatski, postoji intenzivno djelovanje dinamike ventila i elementa za brtvljenje na protok plina kroz ventil. Loše karakteristike ventila neminovno dovode do degradacije rada kompresora i /ili kratkog vijeka trajanja ventila. Kratki vijek trajanja ventila rezultat je prekomjernih udarnih sila između elementa za brtvljenje i drugih dijelova sklopa ventila. Usklađivanje ventila sa specifičnim stapnim kompresorom složen je zadatak koji zahtijeva primjenu odgovarajućih matematičkih modela prije nego se ventil uskladi. U ovom radu predstavljamo matematički model za predviđanje dinamike ventila. Matematički model se provjerava mjerenjima termodinamičkih karakteristika specifičnog stapnog kompresora u motornom vozilu. Zaključeno je da se matematički model dobro slaže s rezultatima laboratorijskih ispitivanja.

Ključne riječi: dinamika ventila; stapni kompresor; ventilski protok

\section{Introduction}

Reciprocating compressors are used in commercial vehicles for obtaining pressurized air for auxiliary purposes, such as braking, gear shifting, etc. The compressor is a rather small component in comparison with the system that it supplies with gas, but its reliability determines the availability and safety of the auxiliary system.

Reciprocating compressor stage consists of a cylinder, the volume of which varies periodically due to the motion of a piston that closes one end of the cylinder. Cylinder is closed by two valve ports, one each for admitting the gas to be compressed into the machine (suction valve), and for allowing the high pressure gas to be delivered to the system utilizing it (discharge valve).

The suction and discharge processes are to be realized exclusively through the respective valves. The key feature of compressor valves is that they are held closed by elastic forces internal or external to the sealing element and they open and close automatically. The latter is in accordance with the balance of gas pressure forces and the previously mentioned elastic ones. Under the gas pressure forces one understands both the force due to static pressure difference across a closed valve and the aerodynamic drag brought about by the gas flow impinging onto the sealing element in a partially or fully open valve. The absence of a reliable guide device that would provide for the plan-parallel motion of the sealing element give rise to non-parallel impacts between the latter and other parts of the valve assembly, which in turn causes premature sealing element fracture and the machine shutdown.

Compressor valves represent the primary cause of unscheduled reciprocating compressor shutdowns, with a relative frequency of $36 \%$. Since the second-ranking cause of machine failure is piston rod packing $(17,8$ $\%)[1]$. One may surmise that valves are responsible for even a larger percentage of failures in small compressors, such as e.g. used to compress air in commercial vehicles.

The objectives of the paper are improving models of dynamic processes in the valves of motor vehicle reciprocating compressors. Paper aims were model results verification by experimental results obtained on the original test bench.

\section{$2 \quad$ Valve modelling}

The dynamics of self-acting compressor valves was first considered in a systematic manner by Costagliola [2]. Although his model assumed stable behaviour of the sealing element, i.e. it did not allow for flutter, it provided a foundation upon which the majority of models developed in its aftermath were built. The developments up to 1972 were reviewed by MacLaren [3] and, somewhat later and in much more detail, by Touber [4]. Bukac [5] attempted to present the entire field of valve dynamics and flow simulation in a compact manner, but his paper should be read as an overview only, for it lacks arguments for choosing particular formulae and treats the flow calculation inconsistently in that a polytrophic change is used simultaneously with the isentropic choking criterion. Habing [1] presents a modern view of the field and includes measurements to verify the theories used.

\subsection{General considerations}

Conceptually, the influence of the valve upon the compressor performance and reliability can be analysed in terms of the following three phenomena, i.e. models: 
1. Mechanical, accounting for the opening and closing processes motion of the spring-mass assembly of the sealing element, and whatever impact processes within the valve. This area is commonly referred to as valve dynamics.

2. Flow, describing the relationships between the mass flow rate through the valve and the gas states in the cylinder and the valve attachments.

3. Coupling i.e. interaction between the valve action and the fluid dynamics at the upstream and downstream sides of the valve.

While the first two phenomena can be studied both analytically and experimentally in isolation from the compressor i.e. by specifying constant or variable fluid states upstream and downstream of the valve, the third one is a system phenomenon and can thus only be analysed together with the cylinder and the attached piping and fittings. Experimentally, the latter calls for measurements at a suitable test bench or in the compressor installation; and analytically, a comprehensive system model are needed that includes all relevant components and processes. Regarding the modelling depth, it was an established practice in the past to lump the respective piping at the suction and discharge sides of the machine into volumes, neglecting thus the wave motion that inherently takes place there. This approach simplifies the plant model considerably, saving also the computation time. The accuracy of performance prediction is affected by the simplification that large differences do exist between the performance figures obtained with the two model assumptions. However, further discussion of this subject is beyond the scope of the present paper.

\subsection{Modelling of the valve dynamics}

In principle, an automatic compressor valve consists of a movable sealing element, a seat against which the latter rests when the valve is closed, means for generating a force that presses the sealing element against the seat, and means for limiting the extent of the sealing element motion when the valve is fully open.

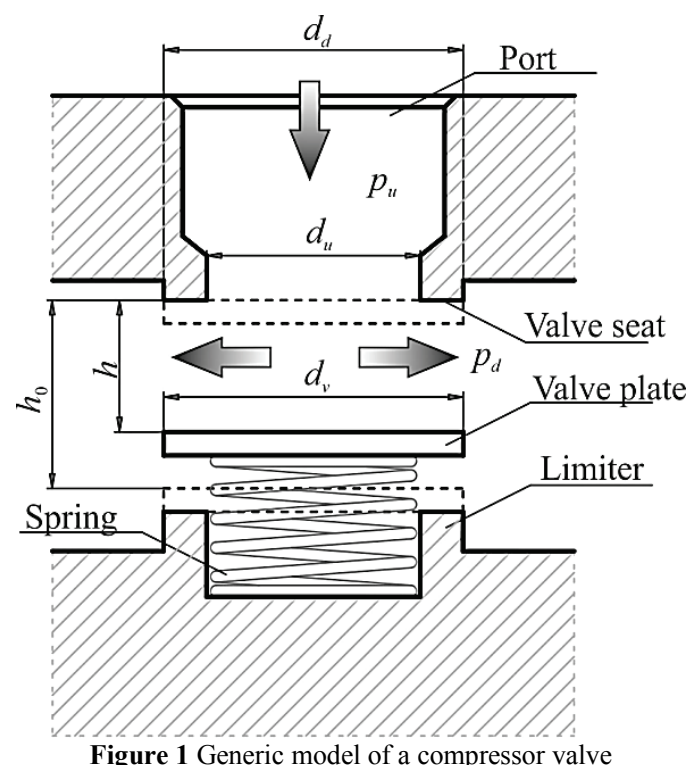

Figure 1 Generic model of a compressor valve
For modelling, all valve designs without a damper plate can be abstracted to a configuration with a single sealing element depicted in Fig. 1.

In order to describe the operation of the valve, one must account for several states, events and processes that take place within the valve assembly. These are:

1. Valve in a closed state.

2. The opening event. When the force due to pressures acting upon the two sides of the plate overcomes the forces holding the plate at the seat, the valve begins to open and the gas starts flowing through the gap. Generally, three forces oppose separation of the plate from the seat, these being the spring force, the stiction force due to a possible oil film at the contact surfaces, and the pressure force due to the unequal areas of the plate exposed to the respective pressures at the two sides of the plate.

3. Plate in motion between the seat and the stroke limiter, subjected to the spring force, the force due to the drag of the gas flowing past the plate, and the fluid friction opposing the motion (process).

4. Impact upon the stroke limiter. Note that there may be repeated impacts before the plate settles down.

5. Valve in a fully open state.

6. The detachment event. When the spring force prevails over the forces holding the valve open, the plate disengages from the stroke limiter. Similarly, to the opening event, oil and/or gas stiction should be modelled (if present).

7. Plate in motion between the stroke limiter and the seat, same as Point 3 above.

8. Impact upon the valve seat. Note that there may be repeated impacts before the plate settles down.

9. Valve in a closed state

\subsection{Valve flow modelling}

Practically in all compressor performance prediction models, energy losses incurred at valves are modelled by measuring the performance of the valve on a test bench, and defining the so-called discharge coefficient as the quotient of the mass flow rate measured, $\dot{m}_{\text {meas }}$, and a reference (ideal) value, $\dot{m}_{\text {ideal }}=\dot{m}_{\text {isen }}$, under the same flow conditions

$\alpha=\frac{\dot{m}_{\text {meas }}}{\dot{m}_{\text {ideal }}}=\frac{\dot{m}_{\text {meas }}}{\dot{m}_{\text {isen }}}$

The reference component used is the ideal nozzle, having the same cross-sectional area at the throat as the valve being modelled. The true mass flow rate through the real valve is then calculated by assuming isentropic expansion between the upstream and downstream conditions, and multiplying the ideal mass flow rate by the discharge coefficient. In reality, the lower mass flow rate through the real device is caused by irreversibility, generating thus entropy in the flow process.

The discharge coefficient concept has its origin in the practice of flow rate measurement by means of standardized flow restrictions, such as e.g. orifices, nozzles, Venturi meters etc. In order to apply this concept to practical mass flow rate calculations, one must merely 
specify a suitable geometric cross-sectional area for the device in question, denoted by e.g. $A_{\text {vg. }}$ Knowing the thermodynamic states at the device inlet and outlet, the actual mass flow rate in subsonic flow is calculated by invoking the well-known Saint-Venant-Wantzel equation of $1839,[6]$ :

$$
\dot{m}=\alpha \cdot \dot{m}_{\mathrm{isen}}=\alpha \cdot A_{\mathrm{vg}} \cdot \frac{p_{\mathrm{u}}}{\sqrt{\mathrm{R} \cdot T_{\mathrm{u}}}} \cdot \sqrt{\frac{2 \cdot \kappa}{\kappa-1}\left(\Pi^{-\frac{2}{\kappa}}-\Pi^{-\frac{\kappa+1}{\kappa}}\right)}
$$

where: $p_{\mathrm{u}}$ - pressure (stagnation) upstream valve, $p_{\mathrm{d}}$ pressure (static) downstream valve, $\Pi=p_{\mathrm{u}} / p_{\mathrm{d}}$ pressure ratio, $\kappa$ - adiabatic index, $\mathrm{R}$ - universal gas constant, $T_{\mathrm{u}}$ - air temperature upstream valve.

The isentropic part of the above formula refers to a reversible outflow from a pipe (hence the stagnation pressure and temperature terms) or a vessel; in the latter case the total pressure and temperature are replaced by their respective static quantities. The term to the right of the cross-sectional area represents the mass flux of the reversible outflow process under the thermodynamic conditions specified. It may be thought of as to result from a flow process taking place in an ideal nozzle, leading thus to the term equivalent nozzle for the reference element used.

The product of the discharge coefficient and the geometric cross-sectional area is referred as the effective cross-sectional area or effective flow area of the valve:

$$
A_{\mathrm{veff}}=\alpha \cdot A_{\mathrm{vg}}
$$

It should be borne in mind that the above formula set does not constitute a valve flow model in the sense of gas dynamics; it is merely a calculation device for arriving at the mass flow rate under given thermodynamic conditions.

Generally, the discharge coefficient for a given valve depends upon the geometric flow area and the pressure ratio across the valve. However, since the term under the square root of Eq. (2) has a maximum under next conditions:

$$
\Pi_{\text {crit }}=[0.5(\kappa+1)]^{\kappa /(\kappa+1)}
$$

For air $\kappa=1.4, \Pi_{\text {crit }}=1.893$, which is called the critical pressure ratio and, since it is an established fact that compressor valves choke at higher-pressure ratios (up to 10); the above equation cannot be used as a mass flow rate model beyond the critical pressure ratio. The information as to the mass flow rate at overcritical pressure ratios must be supplied by the discharge coefficient [6].

\section{Valve dynamics analysis}

Modelling of the valve dynamics in the reciprocating compressor requires that the complex model should be analysed in stages in accordance with the description of stages in the process of opening and closing the valve which was previously given in section 2.2.

\subsection{Force balance at the opening event}

The valve is in a closed state when the following inequality is satisfied:

$$
p_{\mathrm{u}} \cdot A_{\mathrm{u}}-p_{\mathrm{d}} \cdot A_{\mathrm{d}} \leq F_{\mathrm{sc}}+F_{\mathrm{adh}}
$$

where: $A_{\mathrm{u}}$ - upstream plate areas, $A_{\mathrm{d}}$ - downstream plate areas, $F_{\mathrm{sc}}$ - spring force in a closed valve, $F_{\mathrm{adh}}$ - adhesion force.

The valve starts opening when the inequality condition in Eq. (5) reverses, i.e.

$p_{\mathrm{u}} \cdot A_{\mathrm{u}}-p_{\mathrm{d}} \cdot A_{\mathrm{d}}>F_{\mathrm{sc}}+F_{\mathrm{adh}}$

The preload spring force for closed valve state is:

$F_{\mathrm{sc}}=k \cdot h_{\mathrm{s} 0}$

where: $k$ - spring constant, and $h_{\mathrm{s} 0}$ - spring preload length.

The opening process is strongly dependent upon the adhesion force in the contact area between the valve plate and the seat. If no liquid is present in the contact area the adhesion force may be due to molecular forces and/or under pressure; Touber [4] uses the term "stiction" to refer to this phenomenon. He models the adhesion force by expressing it as an integral of the pressure distribution in the contact surface, i.e.

$F_{\mathrm{adh}}=\int_{A_{\mathrm{c}}}\left(p_{\mathrm{u}}-p\right) \mathrm{d} A_{\mathrm{c}}$

where: $A_{\mathrm{c}}$ - contact surface area, $p$ - pressure variation in the film between the valve plate and seat.

The situation is more complicated if liquid is present in the contact area, which is always the case with lubricated machines and/or when the gas carries liquid droplets being compressed. Giacomelli and Giorgetti considered this effect much stronger at the stroke limiter [7].

Khalifa and Liu concentrated on the suction valve stiction at the seat, and concluded that the primary reason for the stiction is the force arising from the oil film in the contact area being dilated in the opening process [8]. Departing from the Reynolds equation of hydrodynamic lubrication:

$\frac{\partial p}{\partial r}=\mu \cdot \frac{\partial^{2} u_{r}(z)}{\partial z^{2}}$

where: $r$ - radial coordinate of the oil film (meniscus), $R_{\mathrm{mi}}$ $\leq r \leq R_{\mathrm{me}}, R_{\mathrm{mi}}$ - internal radius of the meniscus, $R_{\mathrm{me}}-$ external radius of the meniscus, $0 \leq \mathrm{z} \leq h_{\mathrm{f}}-$ axial coordinate, $h_{\mathrm{f}}$ - film thickness, $u_{r}(z)$ - velocity profile, and $\mu$ - dynamic viscosity of oil.

The total force introduced by the oil viscosity, named here like the adhesion force is the integration of the above pressure over the area covered by the oil film, which is calculated mostly by the following general equation: 


$$
F_{\text {adh }}=C \cdot \frac{\dot{z}}{z^{3}}
$$

where $C$ - stiction coefficient.

Generally, the stiction coefficient depends on the geometric features of the valve, and the viscosity of the liquid, e.g. oil, in the valve contact area. Several formulae for calculating the stiction coefficient are available in the literature; for illustration, we quote here two such formulae for the same physical configuration of the valve seat in Tab. 1.

Table 1Formulae for the calculation of the stiction coefficient

\begin{tabular}{|c|c|}
\hline Source & $\begin{array}{c}\text { Stiction force of separation for raised } \\
\text { flat valve seat and oil-starved gap }\end{array}$ \\
\hline $\begin{array}{c}\text { Aigner } \\
{[6]}\end{array}$ & $C=\mu \cdot\left(\frac{d_{\mathrm{d}}-d_{\mathrm{u}}}{2}\right)^{3} \cdot \frac{d_{\mathrm{d}}+d_{\mathrm{u}}}{2}$ \\
\hline $\begin{array}{c}\text { Bukac } \\
{[5]}\end{array}$ & $C=\frac{3 \cdot \pi \cdot \mu \cdot\left(r_{\mathrm{B}}^{4}-r_{\mathrm{A}}^{4}\right)}{32} \cdot\left(\frac{r_{\mathrm{B}}^{2}-r_{\mathrm{A}}^{2}}{\left(r_{\mathrm{B}}^{2}+r_{\mathrm{A}}^{2}\right) \cdot\left(\ln r_{\mathrm{B}}-\ln r_{\mathrm{A}}\right)}-1\right)$ \\
& $r_{\mathrm{A}}=\frac{d_{\mathrm{u}}}{4} \cdot\left(1+\frac{\left.h_{\mathrm{f} 0}\right)+\frac{d_{\mathrm{d}}}{4} \cdot\left(1-\frac{h_{\mathrm{f} 0}}{h}\right)}{4}\right)$ \\
& $r_{\mathrm{B}}=\frac{d_{\mathrm{u}}}{4} \cdot\left(1-\frac{h_{\mathrm{f} 0}}{h}\right)+\frac{d_{\mathrm{d}}}{4} \cdot\left(1+\frac{h_{\mathrm{f} 0}}{h}\right)$ \\
\hline
\end{tabular}

Where: $h_{\mathrm{f} 0}$ - initial thickness of oil film, $d_{\mathrm{u}}$ - diameter of the port (inner diameter of the seat), and $d_{\mathrm{d}}$ - outer diameter of the seat.

The verification of the Eq. (10) is very difficult because of the lack of experimental data.

\subsection{Force balance at a moving valve plate}

As soon as the valve begins to open the gas starts flowing through the gap between the plate and the seat, causing the upstream pressure at the former to diminish, which may in its turn lead to a temporary closure of the valve. This may give rise to an alternation of the opening and closing events i.e. to the "bouncing" of the plate at the seat.

One can write the instantaneous force balance at the plate as:

$m_{\mathrm{p}} \cdot \ddot{h}+F_{\mathrm{r}}+F_{\mathrm{s}}-F_{\mathrm{d}}=0$

where: $m_{\mathrm{p}}$ - valve plate mass, $F_{\mathrm{r}}$ - fluid friction force, $F_{\mathrm{s}}$ spring force, and $F_{\mathrm{d}}$ - drag force exerted upon the valve plate.

This represents a general, single degree of freedom differential equation of the motion of valve plate mass in the direction perpendicular to the valve seat.

Away from the seat and stroke limiter, friction forces opposing the motion and acting upon the moving plate may cause damping; near the seat and at the limiter, there are also the respective partially elastic impacts. The friction force is modelled by assuming proportionality to the velocity of the valve plate $[3,4]$.

$$
F_{\mathrm{r}}=C_{\mathrm{f}} \cdot \dot{h}
$$

where $C_{\mathrm{f}}$ - valve plate damping coefficient.

Touber found that the same value of the damping coefficient applies to both the suction and discharge valves if they are of identical design and size, implying thus the former's independence on the gas density [4]. He also observed a weak dependence of valve plate damping coefficient upon the oil content in the gas, and generally low values of the coefficient.

The same author obtained a very reasonable agreement of experimental data and theoretical results by modelling the friction force as proportional to the spring load and acting in a sense opposite to the velocity of the valve plate.

In most cases, valve spring force can be considered linearly dependent upon the deformation for the small distances over which a valve plate usually travels. The spring force is then given by:

$$
F_{\mathrm{s}}=k \cdot\left(h_{\mathrm{s} 0}+h\right)
$$

Although Eq. (11) one should also take into account the motion of the springs. Touber was concludes that the inertial effect of the springs can be accounted for by adding an equivalent mass equal to one-third of the mass of the spring to the mass of the valve plate [4].

The force that gives rise to the plate motion is the result of pressure distribution in the flow field around the valve plate. It is calculated as the area integral of the gas pressure load present at both sides of the valve plate, and customarily expressed as Touber [4]:

$F_{\mathrm{d}}=C_{\mathrm{d}} \cdot A_{\mathrm{v}} \cdot\left(p_{\mathrm{u}}-p_{\mathrm{d}}\right)$

where: $C_{\mathrm{d}}$ - drag coefficient, and $A_{\mathrm{v}}$ - the valve plate area.

The product $C_{\mathrm{d}} \cdot A_{\mathrm{v}}$ is referred as the effective force area.

The drag coefficient is assumed to be constant for a given valve configuration, but as MacLaren points out; this is rather not the case [3]. Its value is determined empirically. However, Touber demonstrated a theoretical way to determine this coefficient by applying the momentum equation to a control volume enclosing the valve plate [4], obtaining:

$$
C_{\mathrm{d}}=\left[1+\left(\alpha \cdot \varepsilon \cdot \frac{\pi \cdot d_{\mathrm{v}} \cdot h}{A_{\mathrm{u}}}\right)^{2}\right] \cdot \frac{A_{\mathrm{u}}}{A_{\mathrm{v}}}-\frac{\left[\alpha \cdot \varepsilon \cdot\left(A_{\mathrm{v}}-A_{\mathrm{u}}\right)\right]^{2}}{A_{\mathrm{v}}-A_{\mathrm{u}}}
$$

where: $\alpha$ - flow coefficients, and $\varepsilon$ - expansion coefficients.

Valve plate and the associated springs constitute a potentially oscillating system; the excitation necessary to give rise to oscillations is provided by the interaction of this system with the flow. This phenomenon is referred to as flutter, and since it can lead to premature valve plate failures it was investigated by several researches in the field. In an early work by Upfold, experimental records of valve motion were used to arrive at design criterions a valve/spring system should fulfil in order to avoid flutter [9]. An approximate relationship between design 
parameters and operation conditions of valve when oscillations or flutter of the inlet valve would not occur is defined as:

$$
\omega \cdot p_{\mathrm{u}}>\frac{k^{1.5} \cdot h_{0}}{3 \cdot C_{\mathrm{d}} \cdot A_{\mathrm{v}} \cdot m_{\mathrm{p}}^{0.5}}
$$

Good design of inlet valves would be to ensure that the value $\left(\omega \cdot p_{\mathrm{u}}\right)$ is preferably never less than twice the calculated value of the parameter on the right hand side of Eq. (16) [9].

\subsection{Valve plate impacts}

Impacts between the valve plate and the seat or stroke limiter give rise to stress concentration, leading to impact fatigue, which in its turn affects the service life of the plate. No generic modelling of the impacts seems to be possible, for the phenomena involved are rather complex. For example, it is questionable whether the classical impact between two solid bodies takes place in this case because, as the valve plate approaches either of the two limiting elements, it displaces the gas and oil present in the gap, adding thus a further mechanism to the impact process.

The valve plate is limited in its travel by the valve seat and in most valve designs by a limiter. It is assumed in the following that this limiter is fixed at an arbitrary distance from the seat and will not change its position when hit by the moving valve plate. When a moving body impacts at a fixed wall it will rebound with a velocity that is generally lower than the velocity before the impact. Only when its kinetic energy is absorbed or dissipated completely, it will remain in contact with the wall.

For the case that the valve plate rebounds, Habing defines the so-called restitution coefficient as the ratio of the plate velocities immediately after $\left(t^{+}\right)$and before $\left(t^{-}\right)$ the impact [1], i.e.

$$
\left.\frac{\mathrm{d} h}{\mathrm{~d} t}\right|_{\left(t^{+}\right)}=-\left.e_{\text {res }} \cdot \frac{\mathrm{d} h}{\mathrm{~d} t}\right|_{\left(t^{-}\right)} .
$$

An impact is referred to as elastic when $\left(e_{\text {res }}=1\right)$, inelastic when $\left(e_{\text {res }}=0\right)$ and semi-elastic when $\left(0<e_{\text {res }}<1\right)$. During proper experiments Habing obtained $\left(e_{\text {res }, s}=0,3 \pm 0,1\right)$ and $\left(e_{\text {res }, l}=0,2 \pm 0,1\right)$ for the impacts of the valve plate at the seat and stroke limiter, respectively [1].

\subsection{Valve in fully open state}

A valve is open when the sum of forces holding the valve plate at the stroke limiter prevails over the spring force, $F_{\text {so }}$ which is expressed by the following inequality:

$$
F_{\text {so }} \leq F_{\mathrm{d}}+F_{\text {adh }} \text {. }
$$

The adhesion force may be due to oil stiction or the vacuum between the latter valve parts.

\subsection{Force balance at the detachment event}

Note that this event is not the counterpart to the valve opening; it can be understood as the onset of the valve plate motion toward the seat. The condition for this to take place is:

$$
F_{\text {so }} \geq F_{\mathrm{d}}+F_{\text {adh }}
$$

After this event is completed, motion of the valve plate proceeds in accordance with the relationships derived in the previous section on valve plate motion.

\section{Experimental and simulation results}

In order to illustrate some of the concepts and models discussed above, simulation of a small single-cylinder air compressor for motor vehicles, with characteristics presented in Tab. 2, was performed with a compressor simulation program that can also consider unsteady flow in the valve chambers and attached piping.

Table 2 Characteristics of the experimental compressor

\begin{tabular}{|l|c|}
\hline \multicolumn{1}{|c|}{ Description } & Value \\
\hline Cylinder volume, $\mathrm{cm}^{3}$ & 150 \\
\hline Clearance volume, $\mathrm{cm}^{3}$ & 12,7 \\
\hline Cylinder Diameter $\times$ Stroke, $\mathrm{mm}$ & $74 \times 35$ \\
\hline Crank radius, $\mathrm{mm}$ & 17,5 \\
\hline Connecting rod length, $\mathrm{mm}$ & 137 \\
\hline Valve plate maximal stroke, $\mathrm{mm}$ & 1,4 \\
\hline Valve plate outside diameter, $\mathrm{mm}$ & 30,5 \\
\hline Mass of moving valve parts, $\mathrm{kg}$ & $3,8 \times 10^{-3}$ \\
\hline Mass of equipped piston, $\mathrm{kg}$ & 0,215 \\
\hline Number of suction/discharge ports & $1 / 1$ \\
\hline Suction pipe length, mm & 50 \\
\hline Discharge piping length, $\mathrm{mm}$ & 1700 \\
\hline Discharge pressure, $\mathrm{MPa}$ & $0,1 \div 1$ \\
\hline
\end{tabular}

The compressor is currently being experimentally investigated on a custom test bench for small air compressors in the Laboratory for IC Engines of the Faculty of Engineering, University of Kragujevac, Republic of Serbia.

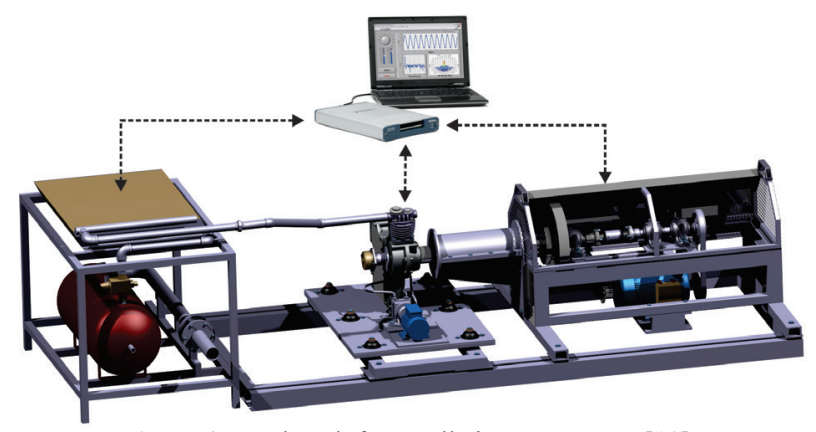

Figure 2 Test bench for small air compressors [10]

The test bench is schematically presented on Fig. 2 . The experimental plate valve-reciprocating compressor projected for the braking system of heavy-duty vehicles and buses, suspended on elastic rack was powered by a squirrel-cage motor, which is fixed on welded rack of box-shaped profiles. Power unit consists of the electric squirrel-cage motor powered by frequency inverter. The 
compressor's elastic shaft with axial unloader is connected to pulley, freewheel, clutch with axial unloader [10].

Measuring installation also consists of a torque transducer, engine speed transducer, and optical encoder measuring crankshaft angle. The compressor speed is controlled by LabView software or manually via a potentiometer on the control panel. The compressor is connected to the tank with capacity 55 litres. The pressure is maintained by use of the governor valve controlled also by LabView software.

The cylinder pressure, $p_{\mathrm{c}}$, is measured using a watercooled piezoelectric transducer (model: QC32D, Manufacturer: AVL). The signal of pressure is amplified with a charge amplifier (model: 5007, manufacturer: Kistler).

The test bench allows recording several quantities of importance for evaluating thermodynamic performance of the machine under test, such as cylinder pressure, exit mass flow rate, gas temperatures etc. Data recorded at an operating point characterized by the delivery pressure of $0,5 \mathrm{MPa}$ and the machine speed of $500 \mathrm{rpm}$ and $1500 \mathrm{rpm}$ were selected for comparison with the simulation.

The model included all pipes up to the heat exchanger; due to the lack of the heat transfer data, the latter was modelled as a volume discharging the gas through a resistance to the environment. Because of the intricate construction of the cooler, it was felt that a major part of the pulsations on the discharge side would be dissipated in the latter, obviating thus the need for including the rest of the piping in the simulation model. All cylinder walls were assumed adiabatic $[11,12,13]$.

The valve simulation model consisted of the following sub models:

- Valve opening force balance without oil stiction, but with finite seat land area, i.e. $d_{\mathrm{d}} \neq d_{\mathrm{u}}$ (see Fig. 1);

- Calculation of the friction, spring, and drag forces per Eq. $(11) \div(14)$, respectively; the drag and friction force coefficients are assumed to be constant;

- Valve plate impacts at the seat and stroke limiter per Eq. 16, and the restitution coefficient values within the bounds established by Habing[1];

- Valve mass flow rate calculation by means of the discharge coefficient model, as defined by Eq. (1) (4).

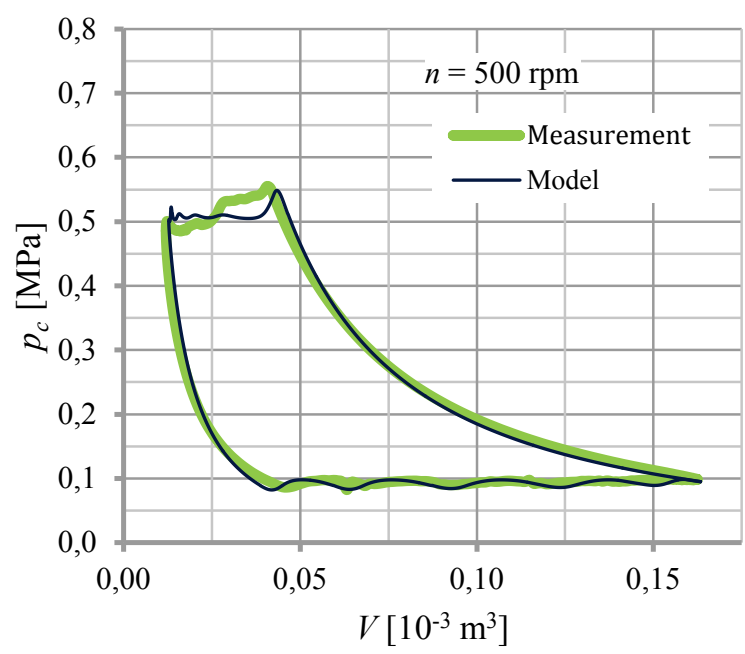

Figure 3 Calculated vs. measured indicator diagram on $n=500 \mathrm{rpm}$

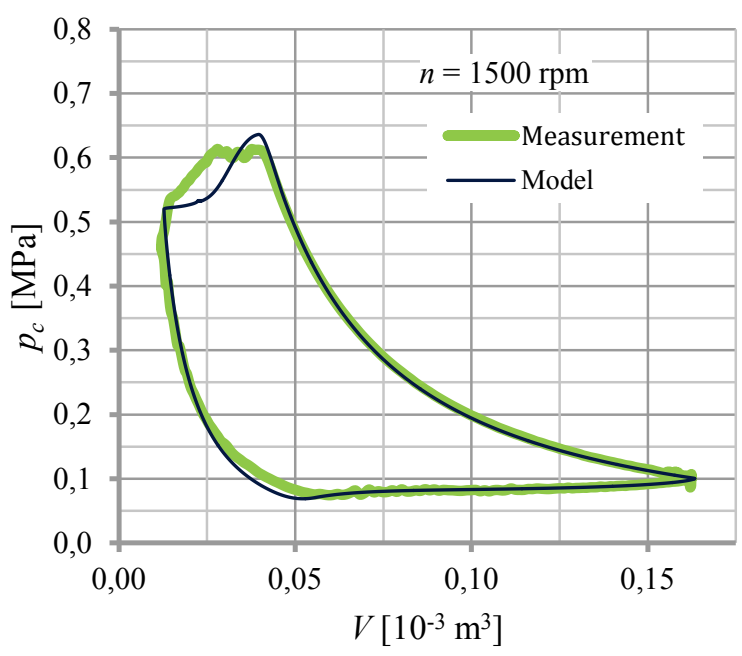

Figure 4 Calculated vs. measured indicator diagram on $n=1500 \mathrm{rpm}$
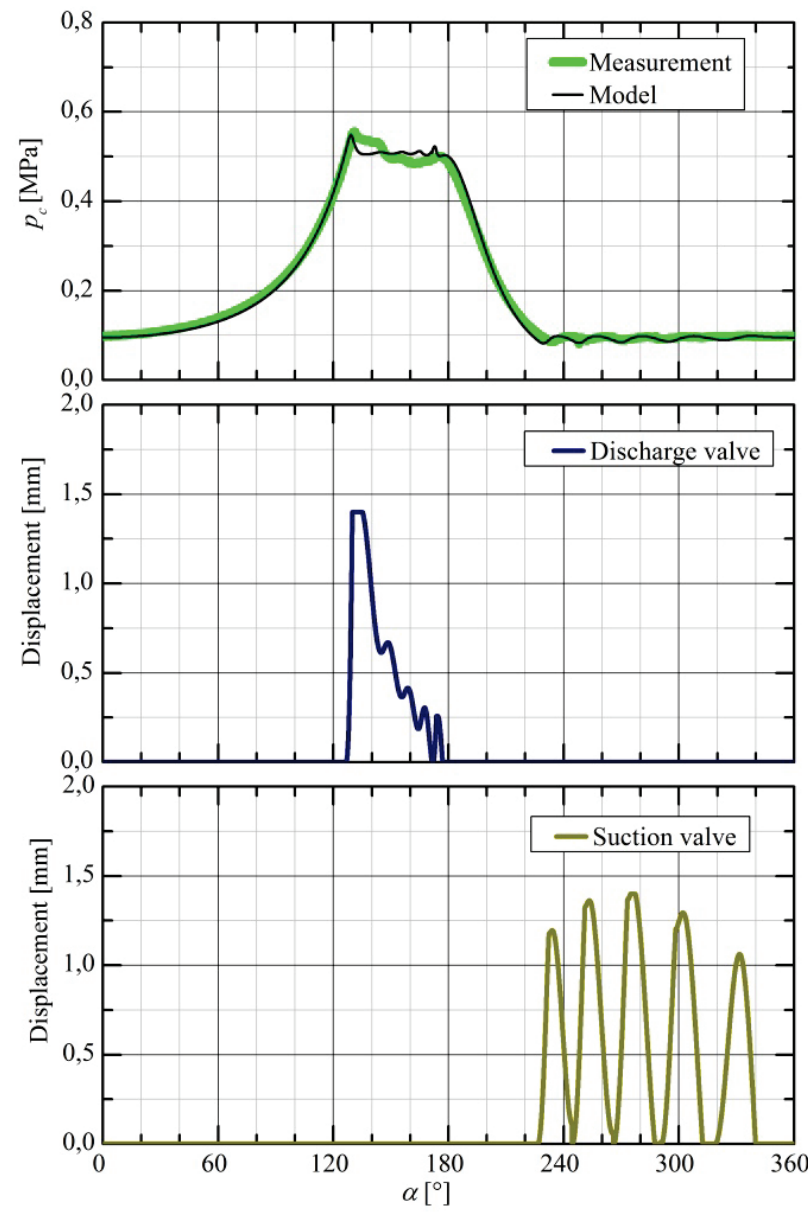

Figure 5 Pressure traces and calculated valve displacements

Referring to Fig. 3, the calculated indicator diagram in terms of pressure is compared to the one obtained by averaging 40 measured cycles. Despite the rather simple valve and cylinder models used, the agreement is satisfactory, except for the discharge process, where an average good agreement is achieved.

On the indicator diagram, shown in Fig. 3, the pressure variations in the cylinder are evident, especially at the suction stage, which are the result of the valve dynamics. At low piston speeds, caused by a small number of revolutions of the engine, variations of the drag force acting on the valve are slow, which enhances the influence of valve dynamics on the working processes in 
the compressor. By increasing the speed of the electric motor, the influence of valve dynamics is reduced. Fig. 4 shows the indicator diagram obtained at higher speeds of the electric motor $(1500 \mathrm{rpm})$. A pressure variation in the cylinder which is a consequence of the valve dynamics is not observed in Fig. 4.

Recording of the valve displacement during the compressor operation is difficult to realize and therefore, the simulation of the compressor valve displacement related to measured and the simulated pressure in the cylinder illustrated by an open indication diagram at 500 rpm is shown in Fig. 5.

By analysing the simulation of the valve displacement as shown in Fig. 5, it can be seen valves fluttering. This is especially noticeable in the case of the suction valve due to smaller pressure difference, which forms the drag force of valve displacement. Simulation of the valve displacement follows all changes in pressure in the compressor cylinder.

\section{Conclusions}

The analysis of the relevant literature led to the conclusion that the modelling of the valve dynamic in the reciprocating compressor is still the research subject. Problem of direct measurements of the dynamics of a valve's sealing element is the reason for still using onedimensional models, although the available hardware and software allow applications of more complex, multidimensional models.

The mathematical model of the reciprocating compressor's valves presented in the paper showed a good agreement with the measurement results of the thermodynamic process in the cylinder of the reciprocating compressor. The results of measurements of thermodynamic processes at low revs of the compressor make it possible to recognize indirectly the impact of the valve dynamics, which is in good agreement with the results of mathematical modelling.

Improvement of the mathematical model of valve dynamic of the reciprocating compressor requires performing appropriate laboratory testing directly on the valve and that based upon the results, determining the dominant influence of the specific process on the operation of the valve.

\section{Acknowledgment}

The paper is the result of the researches within the project TR 35041 that is supported by the Ministry of Education, Science and Technological Development of the Republic of Serbia.

\section{References}

[1] Habing, R. A. Flow and Plate Motion in Compressor Valves. PhD Thesis, University of Twente, 2006.

[2] Costagliola, M. Theory of Spring-Loaded Valves for Reciprocating Compressors. // Trans. ASME, J. Appl. Mech., 17. 4(1950), pp. 415-420.

[3] MacLaren, J. F. T. Review of Simple Mathematical Models of Valves in Reciprocating Compressors. // Proceeding of the International Purdue Compressor Conference / West Lafayette, 1972, pp. 180-187.
[4] Touber, S. A Contribution to the Improvement of Compressor Valve Design. PhD Thesis, TU Delft, 1976.

[5] Bukac, H. Understanding Valve Dynamics. // Proceeding of the International Purdue Compressor Conference / West Lafayette, 2002, Paper 1564.

[6] Aigner, R. Internal Flow and Valve Dynamics in a Reciprocating Compressor. PhD Thesis, Tech. Univ. Vienna, 2007.

[7] Giacomelli, E.; Giorgetti, M. Evaluation of Oil Stiction in Ring Valves. // Proceeding of the International Purdue Compressor Conference / West Lafayette, 1974, pp.167170.

[8] Khalifa, H. E.; Liu, X. Analysis of Stiction Effect on the Dynamics of Compressor Suction Valve. // Proceeding of the International Purdue Compressor Conference / West Lafayette, 1998, pp. 87-92.

[9] Upfold, R. W. Designing Compressor Valves to Avoid Flutter. // Proceeding of the International Purdue Compressor Conference / West Lafayette, 1972, pp. 400406.

[10] Taranović, D. The test bench for non-standard testing of reciprocating compressors for motor vehicles. PhD Thesis, Faculty of Engineering, University of Kragujevac, 2013.

[11] Jingming, J.; Weirong, H. Valve Dynamics and Thermal Cycle Model in Stepless Capacity Regulation for Reciprocating Compressor. // Chinese Journal of Mechanical Engineering, 25, 6(2012), pp. 1151-1160. https://doi.org/10.3901/CJME.2012.06.1151

[12] Prakash, R.; Singh, R. Mathematical Modelling and Simulation of Refrigeration Compressors. // Proceeding of the International Purdue Compressor Conference / West Lafayette, 1974, pp. 274-285.

[13] Venkatesan, J.; Nagarajan, G.; Seeniraj, R. V.; Murugan, R. Experimental Validation of a Mathematical Model of a Reed-Valve Reciprocating Air Compressor from an Automotive-Braking System. // International Journal of Automotive Technology. 11, 3(2010), pp. 317-322. https://doi.org/10.1007/s12239-010-0039-8

\section{Authors' addresses}

Dragan Taranović, Assistant Professor Ph.D. Faculty of Engineering, University of Kragujevac Sestre Janjic 6, 34000 Kragujevac, Serbia E-mail: tara@kg.ac.rs

\section{Dobrivoje Ninković, Ph.D.}

ABB Turbo Systems Ltd

Ruchwiesenstr. 28, Winterthur 8404, Switzerland E-mail: dobrivoje.ninkovic@ch.abb.com

Aleksandar Davinić, Assistant Professor Ph.D. Faculty of Engineering, University of Kragujevac Sestre Janjic 6, 34000 Kragujevac, Serbia E-mail: davinic@kg.ac.rs

Radivoje Pešić, Full Professor Ph.D.

Faculty of Engineering, University of Kragujevac Sestre Janjic 6, 34000 Kragujevac, Serbia E-mail: pesicr@kg.ac.rs

Jasna Glišović, Assistant Professor Ph.D.

Faculty of Engineering, University of Kragujevac Sestre Janjic 6, 34000 Kragujevac, Serbia

E-mail: jaca@kg.ac.rs

Saša Milojević, M.S.

Faculty of Engineering, University of Kragujevac Sestre Janjic 6, 34000 Kragujevac, Serbia

E-mail: tiv@kg.ac.rs 